\title{
miRNA in Rat Liver Sinusoidal Endothelial Cells and Hepatocytes and Application to Circulating Biomarkers that Discern Pathogenesis of Liver Injuries
}

\author{
Shingo Oda, ${ }^{*}$ Masaki Takeuchi, ${ }^{*}$ Sho Akai, ${ }^{*}$ Yuji Shirai, ${ }^{*}$ Koichi Tsuneyama, ${ }^{\dagger}$ and Tsuyoshi Yokoi*
}

From the Department of Drug Safety Sciences, * Division of Clinical Pharmacology, Nagoya University Graduate School of Medicine, Nagoya; and the Department of Molecular and Environmental Pathology, ${ }^{\dagger}$ Institute of Health Biosciences, Tokushima University Graduate School, Tokushima, Japan

Accepted for publication December 7, 2017.

Address correspondence to Shingo Oda, Ph.D., Department of Drug Safety Sciences,

Division of Clinical Pharmacology, Nagoya University Graduate School of Medicine, 65 Tsurumai-cho, Showa-ku, Nagoya 466-8550, Japan. E-mail: shingo61@med. nagoya-u.ac.jp.

\begin{abstract}
Sinusoidal obstruction syndrome is a serious liver injury caused by toxic injury to liver sinusoidal endothelial cells (LSECS) during clinical chemotherapy. Although circulating miRNAs, such as hepatocyte-specific miR-122-5p and miR-192-5p, have been proposed as potential noninvasive biomarkers of hepatocellular liver injury, these miRNAs may not be specific to damage to other hepatic cell types, including LSECs. We characterized miRNA expression in LSECs and hepatocytes and investigated whether cell type-specific miRNAs in plasma can discern pathogenesis of liver injuries in rats. Comprehensive miRNA expression analyses found that 66 and 12 miRNAs were highly expressed in LSECs and hepatocytes isolated from nontreated rats, respectively. An LSEC-enriched miR-511-3p was relatively liver specific according to public data. For establishing LSEC and hepatocyte injury models, rats were orally treated with monocrotaline and thioacetamide, respectively. In monocrotaline-treated rats, a sinusoidal obstruction syndrome model, LSEC damage was observed 6 hours after dosing, whereas hepatocellular damage was observed after 48 hours. Interestingly, the level of miR-511-3p in plasma was increased as early as 6 hours after monocrotaline dosing, followed by an increase of miR-122-5p after 24 hours. In the thioacetamide-induced hepatocellular injury model, the level of miR-511-3p was not altered in plasma, whereas miR-122-5p levels were increased after 6 hours. In conclusion, we identified miR-511-3p in plasma as a possible biomarker for LSEC damage. (Am J Pathol 2018, 188: 916-928; https://doi.org/10.1016/j.ajpath.2017.12.007)
\end{abstract}

Liver is an important organ for the metabolism and detoxification of endogenous and exogenous compounds, hormone and bile acid synthesis, and lipid metabolism. The liver is a heterogenous organ composed of functionally and morphologically different cell types. Parenchymal cells, namely hepatocytes, account for $60 \%$ to $70 \%$ of the total liver cell population and $90 \%$ of the total liver mass. ${ }^{1}$ This cell is responsible for the synthesis and storage of glycogen, protein, and fat. Nonparenchymal cells contain several cell types, including cholangiocytes ( $2 \%$ to $3 \%$ ), liver sinusoidal endothelial cells (LSECs) (15\% to 20\%), Kupffer cells (15\%), and Stellate cells (5\% to $8 \%) .{ }^{1}$ LSECs line the hepatocytes across the space of Disse and play a significant role in the transport of molecules from the circulating blood to the hepatocytes ${ }^{2,3}$ and in the endocytosis of collagen, chondroitin, and hyaluronan, as well as immune complex formed with IgG through specific receptors. ${ }^{4}$
Liver diseases have become a worldwide problem because of the significant morbidity and mortality associated with them. Various causal factors for liver dysfunction are known, including viruses, parasites, environmental toxins, excess alcohol intake, and medicines. As biomarkers for liver injury, alanine aminotransferase (ALT) and aspartate aminotransferase (AST) are the most widely used in both nonclinical and clinical assessment. However, their distribution is not limited to the liver; ALT is also expressed in the kidney, heart, and skeletal muscle. ${ }^{5}$ Because of this, ALT does not always reflect the liver injury. In addition, ALT and AST are enriched in the hepatocytes but not in the other hepatic cell types. During

Supported by a grant from the Research Foundation for Pharmaceutical Sciences, Japan (S.O.), and Grant-in-Aid for Young Scientists (B) 15K21057 from the Japan Society for the Promotion of Science (S.O.).

Disclosures: None declared. 
chemotherapy, LSECs might be injured, leading to sinusoidal obstruction syndrome (SOS), which is a severe liver injury associated with a mortality rate as high as $80 \%{ }^{6}$ Thus, the discovery and development of biomarkers for injuries of other hepatic cell types, especially LSECs, are required.

miRNAs are endogenous noncoding RNAs of approximately 20 nucleotides in length that act as posttranscriptional regulators of gene expression by base pairing to a target mRNA. To date, 2588, 1915, and 765 miRNAs of human, mouse, and rat, respectively, are registered in the miRbase database (version 21), with a large number being conserved across species. ${ }^{7,8}$ miRNAs are expressed in tissue-specific and cell type-specific manners, ${ }^{9}$ thus attracting attention as a novel class of disease or injury biomarkers. The first report of serum miRNAs in liver injury was by Wang et al. ${ }^{10}$ They found that miR-122-5p in plasma was increased in acetaminopheninduced liver injury in mice. Importantly, the level of miR-122-5p began to increase earlier than that of ALT. However, to date, use of circulating miRNAs as biomarkers for liver cells other than hepatocytes has not been reported. One reason for this may be the unavailability of the difference in expression profiles of miRNAs in liver cell types.

In this study, we focused on the hepatocytes and LSEC for the analysis of miRNA expression profiles. LSECs are often injured by chemotherapy or radiotherapy before hematopoietic stem cell transplantation. The transcriptome of miRNA in rat LSECs and hepatocytes was first investigated. Then, tissue specificity of each cell-enriched miRNA was assessed using publicly available miRNA expression profiles in various rat organs. Finally, the levels of selected miRNAs in plasma of monocrotaline- and thioacetamideinduced liver injuries, which cause primarily LSEC and hepatocyte damage, respectively, were investigated.

\section{Materials and Methods}

\section{Animals and Ethics Statement}

Male Sprague-Dawley rats were obtained from Japan SLC (Hamamatsu, Japan). The rats were housed under a controlled environment (12-hour lights on and off cycle, temperature of $23^{\circ} \mathrm{C} \pm 2{ }^{\circ} \mathrm{C}$, and humidity of $55 \% \pm 10 \%$ ) in the institutional animal facility, with ad libitum access to food and water. The rats were acclimated to our facility before the experiments. All animal experiments were approved by the Animal Care Committee of Nagoya University Graduate School of Medicine and were conducted in accordance with the guidelines established by the Institute for Laboratory Animal Research of the Medical School of Nagoya University.

\section{Isolation of Hepatocytes and LSECS}

Ten-week-old male Sprague-Dawley rats were used as the source of cells in this study. The rats were subjected to two-step collagenase perfusion as previously described. ${ }^{11}$ In brief, rats were anesthetized intraperitoneally with $60 \mathrm{mg} / \mathrm{kg}$ of sodium pentobarbital, and the portal vein was cannulated with a 20-gauge catheter. The liver was perfused in situ through the portal vein with $\mathrm{Ca}^{2+}$-free and $\mathrm{Mg}^{2+}$-free Hanks' balanced salt solution (HBSS, pH 7.4; Life Technologies, Carlsbad, CA) containing $10 \mathrm{mM}$ HEPES, $5.5 \mathrm{mM}$ glucose, and $0.53 \mathrm{mM}$ EGTA at $37^{\circ} \mathrm{C}$ at a flow rate of $10 \mathrm{~mL} /$ minute for 15 minutes. The liver was subsequently perfused with HBSS (pH 7.4) containing $0.05 \%$ collagenase (Wako Pure Chemical Industries, Osaka, Japan), $10 \mathrm{mM}$ HEPES, and $5.4 \mathrm{mM} \mathrm{Ca}^{2+}$ at a flow rate of $10 \mathrm{~mL} /$ minute for 15 minutes. The digested liver was excised and minced in Dulbecco's modified Eagle's medium (DMEM; Nissui Pharmaceutical, Tokyo, Japan) containing 10\% fetal bovine serum (FBS; Sigma-Aldrich, St. Louis, MO), and the resulting cell suspension was filtered through a $100-\mu \mathrm{m}$ cell strainer. The cells were then centrifuged at $4{ }^{\circ} \mathrm{C}$ at $50 \times g$ for 3 minutes, and the resulting cell pellet and supernatant were used for hepatocyte and LSEC isolation, respectively. For hepatocyte isolation, the cell pellet was suspended in 10\% FBS and DMEM and centrifuged at $50 \times g$ for 3 minutes twice. The pellet was again resuspended in $25 \mathrm{~mL}$ of $10 \%$ FBS and DMEM and $25 \mathrm{~mL}$ of $90 \%$ Percoll (GE Healthcare, Fairfield, CA) at $200 \times g$ for 10 minutes. The viable hepatocytes (pellet) were collected and washed with 10\% FBS and DMEM. For LSEC isolation, the above supernatant was centrifuged at $4{ }^{\circ} \mathrm{C}$ at $50 \times g$ for 3 minutes and collected by centrifugation at $500 \times g$ for 7 minutes. The pellet of crude nonparenchymal cells (NPCs) was resuspended in $20 \mathrm{~mL}$ of HBSS, and a 2-mL aliquot each was layered on top of a discontinuous iodixanol gradient consisting of $6 \mathrm{~mL}$ each of $11.7 \%$ and $17.6 \%$ (vol/ vol) iodixanol (Axis-Shield, Dundee, Scotland) in a $15-\mathrm{mL}$ tube and centrifuged at $4^{\circ} \mathrm{C}$ at $500 \times g$ for 7 minutes with no brake. NPCs were collected from interfaces of $11.7 \%$ to $17.6 \%$ and $11.7 \%$ HBSS layers and washed with HBSS. Isolation of LSEC was conducted as previously described ${ }^{12}$ using the CELLection Pan Mouse IgG Dynabeads magnetic beads (Dynal, Oslo, Norway), which are coated with monoclonal human anti-mouse IgG antibodies by a DNA linker. The beads $(25 \mu \mathrm{L})$ were incubated with $0.5 \mu \mathrm{g}$ of a monoclonal mouse anti-rat hepatic sinusoidal endothelial cell antibody (clone: SE-1; Immuno-biological Laboratories, Fujioka, Japan) at room temperature for 30 minutes. Then, the SE-1 antibody-conjugated beads were mixed with the NPC fraction in phosphate-buffered saline (PBS) containing 0.1\% bovine serum albumin and 2 mM EDTA (pH 7.4) and rotated at $4^{\circ} \mathrm{C}$ for 20 minutes. Bead-bound cells were precipitated by a magnet and washed with PBS containing $0.1 \%$ bovine serum albumin five times. The cells were released by adding $200 \mu \mathrm{L}$ of RPMI 1640 medium (Nissui Pharmaceutical) containing $4 \mu \mathrm{L}$ of DNase I, $1 \% \mathrm{FBS}, 1 \mathrm{mM} \mathrm{Ca}^{2+}$, and $5 \mathrm{mM}$ $\mathrm{Mg}^{2+}$ at room temperature for 15 minutes.

\section{Immunocytochemistry of CK-18}

The isolated hepatocytes were seeded onto a collagen-coated glass-based dish in William's E medium (Life Technologies) 
supplemented with $10 \%$ FBS, $1 \mu \mathrm{M}$ dexamethasone, and 0.1 $\mu \mathrm{M}$ insulin at $1.7 \times 10^{5} \mathrm{cells} / \mathrm{cm}^{2}$ and incubated overnight at $37^{\circ} \mathrm{C}$ in a humidified atmosphere containing $5 \% \mathrm{CO}_{2}$. The cells were fixed with acetone at $-30^{\circ} \mathrm{C}$ for 10 minutes and washed with PBS three times. The cells were then blocked with PBS containing 3\% bovine serum albumin at room temperature for 1 hour, incubated with $10 \mu \mathrm{g} / \mathrm{mL}$ mouse monoclonal anti-cytokeratin (CK)-18 antibody (clone: C-04; Abcam, Cambridge, UK) at room temperature for 2 hours, followed by incubation with $10 \mu \mathrm{g} / \mathrm{mL}$ of an Alexa Fluor 488-conjugated goat anti-mouse IgG (ab150113; Abcam) for 1 hour. Nuclei were stained with $2 \mu \mathrm{g} / \mathrm{mL}$ of Hoechst 33342 (Sigma-Aldrich) for 15 minutes. Dishes were observed with a BZ-9000 fluorescence microscope (Keyence, Osaka, Japan), and the percentage of CK-18-positive cells was determined by examining five randomly selected fields per dish at a 400-fold magnification using BZ-II viewer software (Keyence).

\section{Flow Cytometry Analysis of LSECS}

The isolated LSECs were blocked with a mouse monoclonal anti-rat-CD32 antibody (clone: D34-485; BD PharMingen, San Diego, CA) at $2.5 \mu \mathrm{g} / \mathrm{mL}$ in PBS containing $0.5 \%$ bovine serum albumin at $4{ }^{\circ} \mathrm{C}$ for 5 minutes. Then the cells were stained with anti-CD31 or anti-CD146 antibody. For flow cytometry analysis of CD31, the cells were incubated with an eFluor 660-conjugated mouse monoclonal anti-rat CD31 (platelet endothelial cell adhesion molecule) antibody (clone: TLD-3A12; eBioscience, San Diego, CA) or an eFluor 660-conjugated monoclonal mouse $\mathrm{IgG}_{1} \kappa$ isotype control (eBioscience) at $1 \mu \mathrm{g} / \mathrm{mL}$ in $100 \mu \mathrm{L}$ of PBS containing $0.5 \%$ bovine serum albumin at $4^{\circ} \mathrm{C}$ for 30 minutes. For flow cytometry analysis of CD146, the cells were incubated with an allophycocyanin-conjugated monoclonal recombinant human anti-rat CD146 antibody (clone: REA697; Miltenyi Biotec, Bergisch Gladbach, Germany) or an allophycocyaninconjugated monoclonal recombinant human isotype control (clone: REA293; Miltenyi Biotec) at $1.5 \mu \mathrm{g} / \mathrm{mL}$ in $100 \mu \mathrm{L}$ of PBS containing $0.5 \%$ bovine serum albumin at $4^{\circ} \mathrm{C}$ for 10 minutes. After washing, the cells were analyzed on a Gallios flow cytometer (Beckman Coulter, Brea, CA) with Kaluza software version 1.5 (Beckman Coulter).

\section{Drug Administration}

Six-week-old male Sprague-Dawley rats were orally treated with $160 \mathrm{mg} / \mathrm{kg}$ of monocrotaline (Sigma-Aldrich) in $400 \mathrm{mM}$ potassium phosphate buffer $(\mathrm{pH} 7.4 ; 10 \mathrm{~mL} / \mathrm{kg}$ ) or $100 \mathrm{mg} / \mathrm{kg}$ of thioacetamide (Tokyo Chemical Industry, Tokyo, Japan) in $0.5 \%$ methylcellulose $(5 \mathrm{~mL} / \mathrm{kg})$. At 0 (before), 3, 6, 12, 24, and 48 hours after monocrotaline administration and at 0 (before), 6, 12, and 24 hours after thioacetamide administration, blood was collected from the abdominal aorta in the presence of EDTA•2Na (final concentration $1 \mathrm{mg} / \mathrm{mL}$ ) as an anticoagulant, and then the liver was removed with the rats under isoflurane anesthesia. Plasma was separated from these blood samples by centrifugation at $4^{\circ} \mathrm{C}$ at $1600 \times g$ for 10 minutes. A piece of each left lateral lobe of the liver was fixed in $10 \%$ neutral buffered formalin (Wako Pure Chemical Industries).

\section{Determination of Plasma ALT, AST, and T-Bil Levels}

The ALT, AST, and total bilirubin (T-Bil) levels in the plasma were measured using a Fuji Dri-Chem 4000V analyzer (Fujifilm, Tokyo, Japan) according to the manufacturer's protocol.

\section{Histopathologic Examination}

The formalin-fixed liver specimens were embedded in paraffin, sectioned $(3 \mu \mathrm{m})$, and stained with hematoxylin and eosin for histopathologic examination. For SE-1 immunohistochemistry, the sections were antigen-retrieved with proteinase $\mathrm{K}$ (Dako, Carpinteria, CA) at $37^{\circ} \mathrm{C}$ for 30 minutes, incubated with a mouse monoclonal anti-rat SE-1 antibody (clone: SE- $1,5 \mu \mathrm{g} / \mathrm{mL}$ ) at $4{ }^{\circ} \mathrm{C}$ for overnight and a peroxidase-conjugated secondary anti-mouse IgG antibody (Histofine Simple Stain Rat MAX PO mouse reagent; Nichirei Biosciences, Tokyo, Japan) at $37^{\circ} \mathrm{C}$ for 1 hour, and developed with 3,3'-diaminobenzidine. The sections were counterstained with hematoxylin. The SE-1-positive area was quantified with ImageJ software version $1.50 \mathrm{i}(\mathrm{NIH}$, Bethesda, MD; http://imagej.nih.gov/ij) using five randomly selected fields per section at a 170-fold magnification.

\section{RNA Extraction}

Isolated LSECs and hepatocytes were mixed with $700 \mu \mathrm{L}$ of QIAzol lysis reagent (Qiagen, Hilden, Germany), and total RNA including small RNA was extracted by miRNeasy mini kit (Qiagen) according to the manufacturer's protocol. Rat plasma $(100 \mu \mathrm{L})$ was spiked with $30 \mathrm{pg}$ of synthetic Arabidopsis thaliana miR159a (5'-UUUGGAUUGAAGGGAGCUCUA-3') as a control for the extraction step and then mixed with $750 \mu \mathrm{L}$ of TRizol LS reagent (Life Technologies). Total RNA, including small RNA, was extracted according to the manufacturer's protocol and eluted in $15 \mu \mathrm{L}$ of nuclease-free water.

\section{Microarray Analysis}

The extracted RNA from the isolated hepatocytes $(n=2)$ and LSECs $(n=2)$ was quantified using a Nano Drop (Nano Drop Technologies, Wilmington, DE), and quality was evaluated with the Agilent 2100 Bioanalyzer (Agilent Technologies, Palo Alto, CA). RNA (250 ng) was labeled with a three-dimensional (3D)-Gene miRNA labeling kit and then hybridized with a 3D-Gene rat miRNA oligo chip version 21 containing oligo DNA probes against mature 761 miRNAs (Toray Industries, Kamakura, Japan). After 
Table 1 Sequences of the Primer Pairs Used for the Real-Time PCR

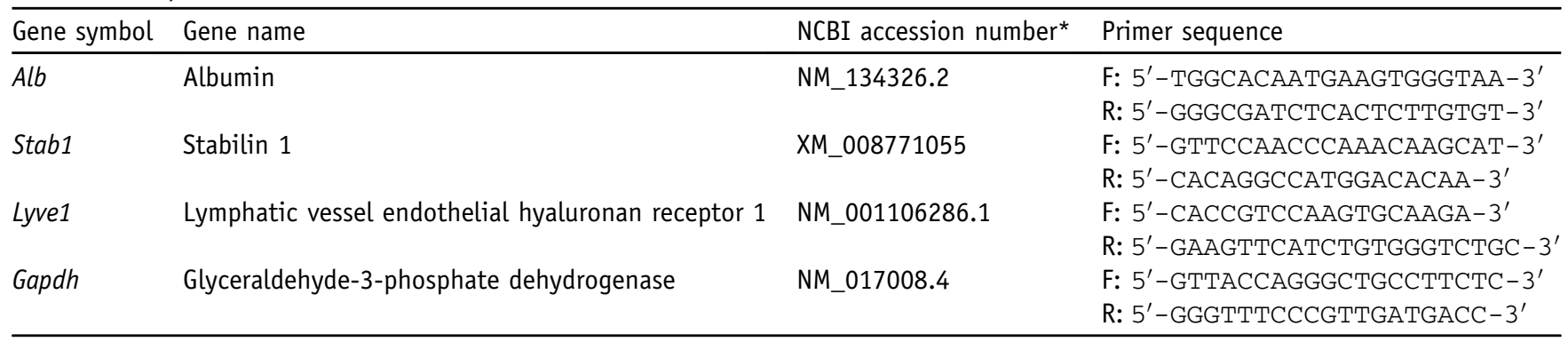

*Searchable on https://www.ncbi.nlm.nih.gov.

F, forward; NBCI, National Center for Biotechnology Information; R, reverse.

washing, fluorescent signals were scanned with the 3D-Gene Scanner 3000 (Toray Industries). Measurements of spots with signal intensities $>2$ SDs of the background signal intensity were considered to be valid. miRNA expression data were scaled by global normalization, such that the median of the signal intensity was adjusted to 25 . Microarray data were deposited in the Gene Expression Omnibus database (https:// www.ncbi.nlm.nih.gov/geo; accession number GSE97229).

\section{Tissue Specificity of miRNAs}

A publicly available miRNA array data set derived from different organs of normal male Sprague-Dawley rats ${ }^{9}$ (GSE52754, with perfusion) was downloaded. The expression of miRNAs in 11 major organs (liver, kidney, lung, heart atrium, stomach anterior, jejunum, ileum, colon, pancreas, spleen, and bladder) was exploited to assess the tissue specificity of the hepatocyte- or LSEC-enriched
miRNAs. miRNA expression data were scaled to the 75th percentile of the median. The normalized signal intensities (mean, 3 rats) were visualized in a heatmap.

\section{Real-Time RT-PCR}

For mRNA analysis, the total RNA extracted from hepatocytes $(n=3)$ and LSECs $(n=5)$ of the normal rats was reverse transcribed using a ReverTra Ace qPCR RT kit (Toyobo, Osaka, Japan) according to the manufacturer's instructions. In brief, $0.5 \mu \mathrm{g}$ of total RNA was mixed with $5 \times$ reverse transcription buffer, reverse transcription enzyme mix, and $0.5 \mathrm{pmol}$ of the primer mix in a total volume of $10 \mu \mathrm{L}$, and the reverse transcription reaction was performed at $37^{\circ} \mathrm{C}$ for 15 minutes and at $98^{\circ} \mathrm{C}$ for 5 minutes using a thermal cycler Dice TP800 (Takara). The expression of Alb (NM_134326.2), Stabl (XM_008771055), Lyve1 (NM_001106286.1), and Gapdh (NM_017008.4) mRNAs
A
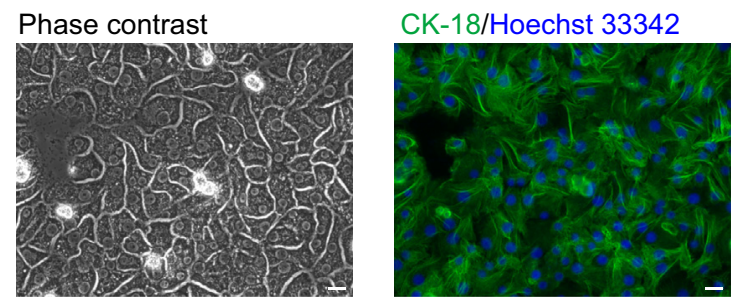

B

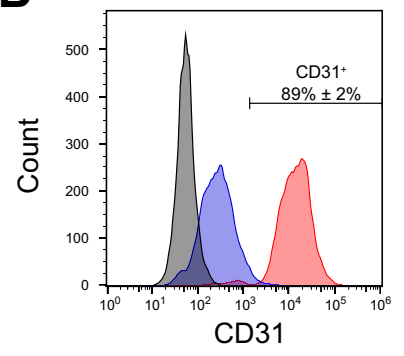

- No antibody

Isotype IgG

- Anti-rat CD31 or CD146

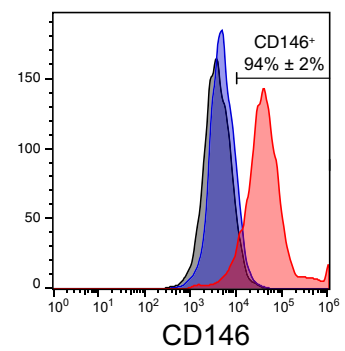

\section{C}

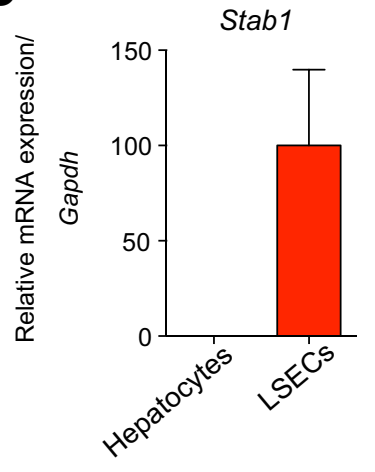

Lyve1

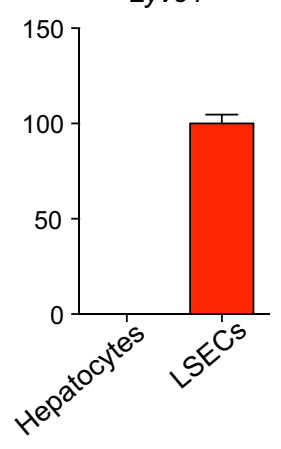

Alb

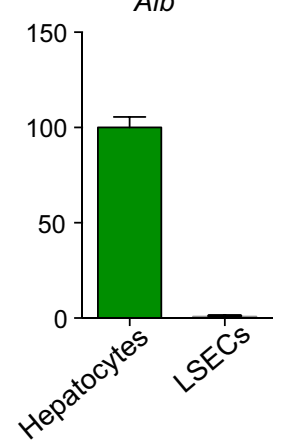

Figure 1 Isolation of liver sinusoidal endothelial cells (LSECS) and hepatocytes from nontreated Sprague-Dawley rats. A: Cytokeratin (CK)-18 immunostaining of the isolated hepatocytes. Nuclei were stained with Hoechst 33342. Green indicates CK-18; blue, Hoechst 33342. B: CD31 and CD146 flow cytometry of isolated LSECs. C: Realtime RT-PCR analyses of Stab1, Lyve1, and Alb mRNA in the isolated LSECs and hepatocytes. Data are expressed as means \pm SEM. $n=3$ hepatocytes $(\mathbf{A}-\mathbf{C}) ; n=5$ LSECS $(\mathbf{A}-\mathbf{C})$. Scale bars $=20 \mu \mathrm{m}(\mathbf{A})$. 
A

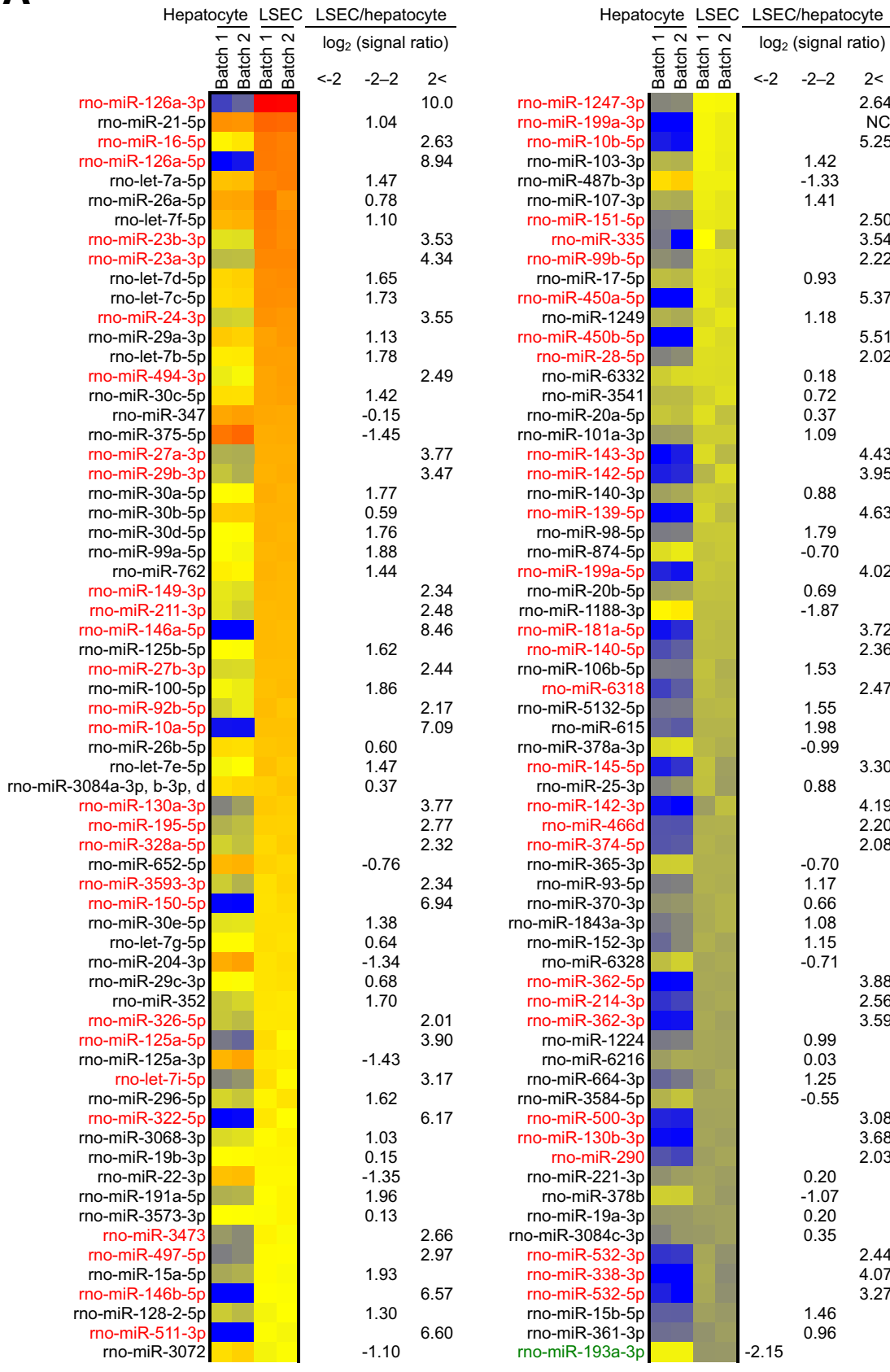

B

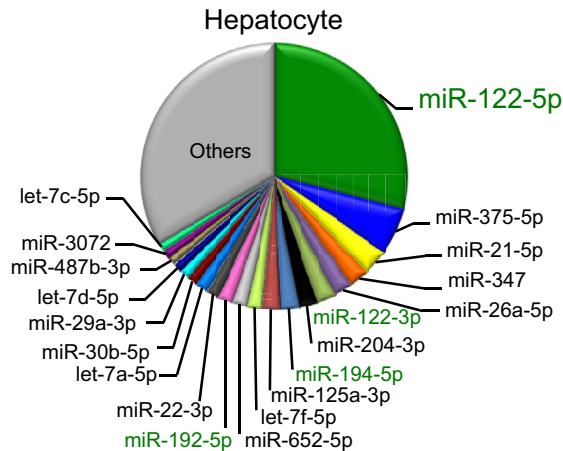

Hepatocyte LSEC LSEC/hepatocyte

$\sim \sim-N \quad \log _{2}$ (signal ratio)

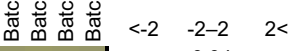

\begin{tabular}{r|r|} 
rno-miR-6215 & -0.04
\end{tabular}

rno-miR-24-2-5p
rno-miR-92a-2-5p

rno-miR-30e-3p

rno-miR-361-5p

rno-miR-3085

rno-miR-30a-3p

rno-miR-365-5p

rno-miR-322-3p

rno-miR-652-3p

rno-miR-92a-3p

rno-miR-667-5p

rno-miR-351-5p

rno-miR-1843b-3p

rno-miR-874-3p

rno-miR-702-3p

rno-miR-1949

rno-miR-666-5p

rno-miR-24-1-5p

rno-miR-223-3p

rno-miR-143-5p

rno-miR-342-3p

rno-miR-139-3p

rno-miR-483-3p

rno-miR-138-2-3p

rno-miR-150-3p

rno-miR-678

rno-miR-667-3p

rno-miR-675-5p

rno-miR-501-3p

rno-miR-345-5p

rno-miR-12

rno-miR-128-1-5p

rno-miR-505-3p
rno-miR-542-3p

rno-miR-186-5p

rno-miR-25-5p
rno-miR-423-5p

rno-miR-423-5p
rno-miR-22-5p

rno-miR-339-5p

rno-miR-295-5p

rno-miR-295-5p
rno-miR-770-5p

rno-miR-770-5p
rno-miR-101b-3p

rno-miR-101b-3p
rno-miR-324-3p

rno-miR-350

rno-miR-212-3p

rno-miR-540-3p

rno-miR-505-5p

rno-miR-148a-3p

mo-miR-193b-3p

rno-miR-664-1-5p

rno-miR-134-3p

rno-miR-378a-5p

rno-miR-664-2-5p

nno-miR-1839-3p

rno-miR-483-5p

no-miR-203a-3p $\quad-2.29$

rno-miR-192-5p

rno-miR-194-5p

rno-miR-122-3p $\quad-7.89$

rno-miR-31a-5p
rno-miR-31a-3p
mo.

rno-miR-802-5p NC

$\log _{2}$ (normalized signal value)

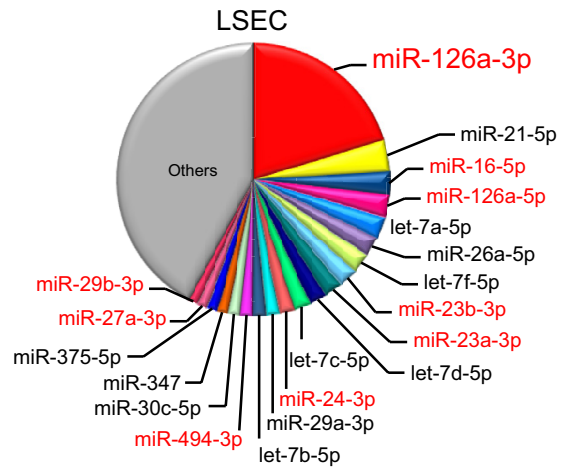


was quantified by real-time PCR. The PCR mixture contained $1 \mu \mathrm{L}$ of the template cDNAs, $5 \mu \mathrm{L}$ of the SYBR Premix Ex Taq solution (Tli RNaseH Plus; Takara, Ohtsu, Japan), $0.2 \mu \mathrm{L}$ of the $50 \times$ ROX reference dye II, and 4 pmol each of the forward and reverse primers in a total volume of $10 \mu \mathrm{L}$. All primers were synthesized at Hokkaido System Science (Sapporo, Japan) (Table 1). Real-time PCR was conducted using an Mx3000P instrument (Agilent Technologies, Santa Clara, CA), with an initial incubation at $95^{\circ} \mathrm{C}$ for 30 seconds, 40 cycles of $95^{\circ} \mathrm{C}$ for 5 seconds, and $60^{\circ} \mathrm{C}$ for 30 seconds. The relative mRNA expression levels were calculated using the comparative $\mathrm{C}_{\mathrm{T}}$ method with Gapdh as the reference gene.

For miRNA analysis, the total RNA $(2.5 \mu \mathrm{L})$ extracted from the plasma and the RNA (50 ng) extracted from the hepatocytes and LSECs were reverse transcribed using a TaqMan miRNA reverse transcription kit and TaqMan miRNA assays, including a specific primer for mature miRNAs (rno-miR-122-5p, assay number 002245; rno-miR-335, assay number 000546; rno-miR-511-3p, assay number 463928_mat; ath-miR159a-3p, assay number 000338; and U6 snRNA, assay number 001973) (Applied Biosystems, Foster City, CA). The reverse transcription reaction was performed at $16^{\circ} \mathrm{C}$ for 30 minutes, $42^{\circ} \mathrm{C}$ for 30 minutes, and $85^{\circ} \mathrm{C}$ for 5 minutes using a thermal cycler Dice TP800. The cDNA was mixed with Taqman Universal PCR mixture and Taqman microRNA assay containing the forward and reverse primers as well as the Taqman probes. Real-time PCR was conducted using a Mx3000P instrument, with an initial incubation at $95^{\circ} \mathrm{C}$ for 10 seconds, 45 cycles of $95^{\circ} \mathrm{C}$ for 15 seconds, and $60^{\circ} \mathrm{C}$ for 60 seconds. The relative miRNA expression levels were calculated using the comparative $\mathrm{C}_{\mathrm{T}}$ method with $A$. thaliana miR159a or U6 snRNA as the reference genes.

\section{Statistical Analysis}

Statistical analyses were conducted using the JMP Pro software version 11.2.1 (SAS Institute, Cary, NC). Comparisons of multiple groups were performed using the Steel test. $P<0.05$ was considered to be statistically significant.

\section{Results}

\section{Isolation of Hepatocytes and LSECs from Nontreated Rats}

To detect hepatocyte- and LSEC-enriched miRNAs, hepatocytes and LSECs were first isolated from nontreated male Sprague-Dawley rats. The means $\pm \mathrm{SD}$ viabilities of isolated LSECs were $90 \% \pm 2 \%$ for isolated LSECs and $90 \% \pm 4 \%$ for hepatocytes. The isolated hepatocytes in culture had the typical cubic shape and high purity of almost $100 \%$ as determined by CK-18 immunostaining (Figure 1A). The LSEC-enriched fraction had means \pm SEM high purities of $89 \% \pm 2 \%$ and $94 \% \pm 2 \%$ as determined by flow cytometric analysis using anti-CD31 and CD146 antibodies, respectively (Figure 1B). The hepatocyte marker $A l b$ and the LSEC markers Stabl and Lyvel were also enriched in the respective cell populations at the mRNA level (Figure 1C).

\section{miRNA Expression Profiles in the Isolated Hepatocytes and LSECs of Nontreated Rats}

miRNA expression profiles in the isolated hepatocytes and LSECs from nontreated rats were investigated by $3 \mathrm{D}-\mathrm{Gene}$ (Toray) rat miRNA oligo chip analysis, which contains probes for 761 mature miRNAs (GSE97229). In total, 656 and 711 miRNAs were detected in hepatocytes and LSECs, respectively. Among these were 131 and 170 miRNAs, respectively, which had signal value $>100$ in either cell type and were further considered (Supplemental Table S1). Cell type-enriched miRNAs were defined as miRNAs whose expression differs by fourfold between each cell. As a result, 12 and 66 miRNAs were found to be overexpressed in hepatocytes and LSECs, respectively, with a fourfold difference or greater (Figure 2A). Pie charts of the top 20 miRNAs expressed in each cell type showed that miR-122$5 \mathrm{p}\left[\log _{2}\right.$ (signal ratio) $\left.=-8.63\right]$ and miR-126a-3p $\left[\log _{2}\right.$ $($ signal ratio $)=10.0]$ were abundantly and solely expressed in hepatocytes and LSECs, respectively, accounting for $29 \%$ and $20 \%$ of all miRNAs expressed (Figure 2B). This study is the first comparison of relative miRNA expression levels in rat hepatocytes and LSECs.

\section{Tissue Distribution of Hepatocyte- or LSEC-Enriched miRNA in Nontreated Rats}

To apply the identified miRNAs as circulating biomarkers for cell type-specific injury, the tissue distribution of the identified hepatocyte- and LSEC-enriched miRNAs was further examined using a publicly available miRNA expression data set in various organs of rats. ${ }^{9}$ A hepatocyte-enriched miR-122-5p was expressed at the highest level in the liver and relatively specific to the liver across the organs (Figure 3A) as previously reported. ${ }^{9}$ Other hepatocyte-enriched miRNAs, including miR-192-5p, miR-122-3p, miR-194-5p, miR-31a-5p, miR-802-5p, and miR-31a-3p, were also relatively specifically expressed in the liver. LSEC-enriched

Figure 2 Characterization of miRNA expression in rat liver sinusoidal endothelial cells (LSECS) and hepatocytes. A: miRNA expression in the isolated LSECS and hepatocytes was analyzed by three-dimensional (3D)-Gene rat miRNA oligo chip. A heatmap represents miRNA expression level (log ${ }_{2}$ of normalized signal value) of 195 miRNAs, showing a normalized signal value of $>100$ in hepatocytes or LSECs. The ratio of miRNA expression in LSECs to hepatocytes is also shown as the $\log _{2}$ value. B: Pie charts of the top 20 highly expressed miRNAs in the isolated rat hepatocytes and LSECs. miRNAs shown in green and red represent hepatocyte- and LSEC-enriched miRNAs, respectively, with a difference of fourfold or greater. Data are expressed as means. $n=2$ rats. NC, not calculated because of the absence of signal in either cell type. 
A
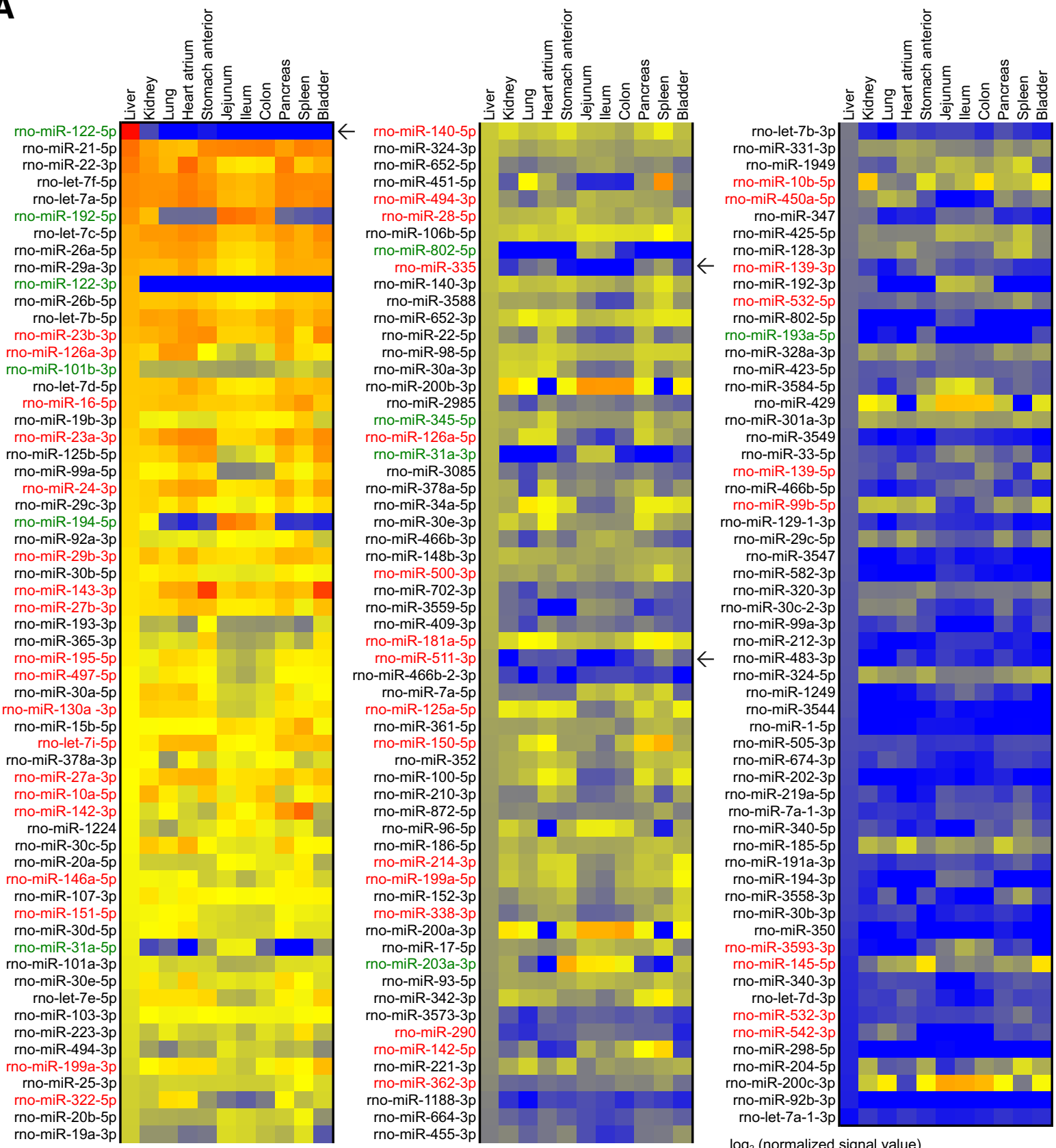

$\log _{2}$ (normalized signal value)

$\begin{array}{lllllllllllllll}2 & 3 & 4 & 5 & 6 & 7 & 8 & 9 & 10 & 11 & 12 & 15 & 16 & 17 & 18\end{array}$

B

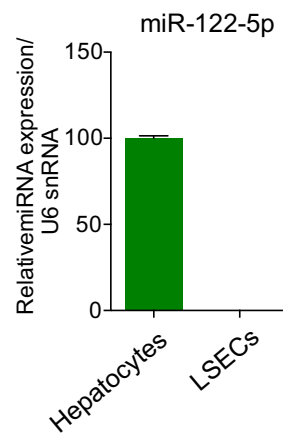

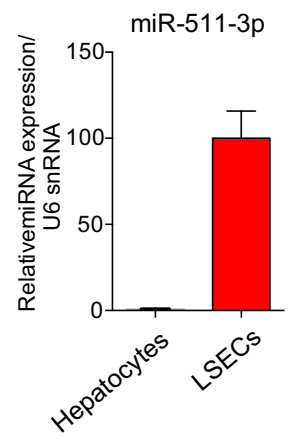


miR-335 and miR-511-3p were found to be relatively specifically expressed in the liver (Figure 3A). Finally, real-time RT-PCR analysis using the isolated rat hepatocytes and LSECs confirmed that miR-122-5p was enriched in hepatocytes and that miR-335, miR-511-3p, and miR-126-3p were enriched in LSECs (Figure 3B). An LSEC-enriched miR-126a$3 p$ was expressed at the 14th highest level in the liver but also expressed in other organs. We hypothesized that miR-122-5p, miR-335, and miR-511-3p might be possible biomarkers for lesions of each cell type.

\section{Alteration of Plasma miRNA Levels in a Monocrotaline- Induced LSEC Injury Model}

Monocrotaline is a toxic pyrrolizidine alkaloid contained in plants of the Crotalaria genus. At hepatotoxic doses of monocrotaline, liver injury is characterized by centrilobular hepatocellular degeneration and necrosis, hemorrhage, and central venous and LSEC injury. ${ }^{13}$ After a single administration of monocrotaline to rats, plasma ALT and AST levels were increased $>500 \mathrm{U} / \mathrm{L}$ at 48 hours after the administration, but the T-Bil level was not altered (Figure 4A). Histopathologic examination found endothelial cell damage in central veins at 6 hours and hepatocellular degeneration and necrosis at 48 hours (Figure 4, B and C, and Supplemental Figure S1). The expression of the LSEC antigen (Fc $\gamma$ RIIB) recognized by the SE-1 antibody was decreased at 6 hours, suggesting that LSEC injury precedes hepatocyte injury (Figure 4, B and C, and Supplemental Figure S1). In plasma, hepatocyte-specific miR-122-5p was increased from 24 hours after the treatment, whereas an LSEC-specific miR-511-3p was increased from 6 hours (Figure 4D). The three miRNAs, including miR-335, were increased at 48 hours. These results indicate that miR-511$3 p$ is released from the damaged LSECs.

\section{Alteration of Plasma miRNA Levels in Thioacetamide- Induced Hepatocellular Injury Model}

To further validate the data, another hepatotoxic compound, thioacetamide, which induces hepatocellular liver injury, was administered to rats. Plasma ALT and AST levels were significantly increased at 12 and 24 hours after the administration (Figure 5A). The plasma T-Bil level was not altered (Figure 5A). Histopathologic examination found the single hepatocellular degeneration and necrosis at 6 hours and massive hepatocellular injury at 24 hours (Figure 5, B and C). Endothelial cell damage in central veins was observed at 12 and 24 hours after the administration
(Figure 5C). The SE-1-positive area in the liver was not decreased from 6 to 12 hours but slightly decreased at 24 hours, although this finding was not significant, suggesting that hepatocyte injury precedes LSEC injury (Figure 5, B and C). These histologic observations warranted the use of thioacetamide-induced liver injury as a hepatocellular injury model. In plasma, miR-122-5p levels were significantly increased at 6 hours. However, plasma miR-335 and miR-511-3p were not altered before the time point of ALT elevation (Figure 5D). The three miRNAs were increased at 24 hours. Taken together, these results further support that miR-511-3p, an LSEC-specific miRNA, is increased in plasma only on LSEC injury because miR-511-3p was unchanged at early time points when LSEC injury was not observed in thioacetamide-induced liver injury.

\section{Discussion}

Circulating microRNAs have attracted attention as a new class of biomarker for organ or cell injuries. Previous studies found that circulating miR-122-5p, which is abundant in the liver, especially in hepatocytes, serves as a marker for hepatocellular liver injury caused by acetaminophen in mice, ${ }^{10}$ rats, ${ }^{14}$ and humans. ${ }^{15}$ However, the miRNA species may not be applicable in detecting injuries in other hepatic cell types, such as LSECs, which are often damaged by chemotherapy. ${ }^{16}$ In this study, we compared the miRNA expression profiles in rat hepatocytes and LSECs, aiming to detect cell type-specific biomarkers for liver injury.

A microarray analysis was first performed to obtain comprehensive expression profiles of miRNAs in isolated hepatocytes and LSECs of nontreated rats. Sixty-six and 12 miRNAs were found to be expressed more than fourfold in LSECs and hepatocytes, respectively, compared with the respective cells. Among them, miR-126a-3p was identified as the most LSEC-enriched miRNA, accounting for $20 \%$ of all miRNAs expressed. miR-126a-3p and its complementary analog, miR-126a-5p, originate from a common precursor that is encoded from an intron of the egfl7 gene in vertebrates. ${ }^{17}$ Studies have found that miR-126a-3p is abundantly expressed in vascularized tissues, endothelial cell lineage, and hematopoietic progenitor cells and plays a critical role in vascular integrity and angiogenesis. ${ }^{18,19}$ Despite the observation of miR-126a-3p as an LSEC-enriched miRNA, the expression of miR-126a-3p was found not to be liver specific, but it was also expressed in various kinds of tissues (Figure 2A). Hence, miR-126a-3p was not adopted as a biomarker for liver

\footnotetext{
Figure 3 Tissue distribution of miRNAs that are abundant in liver sinusoidal endothelial cells (LSECs) or hepatocytes. A: The expression of miRNAs in 11 major organs (liver, kidney, lung, heart atrium, stomach anterior, jejunum, ileum, colon, pancreas, spleen, and bladder) of normal Sprague-Dawley rats were downloaded from a publicly available miRNA array data set (https://www.ncbi.nlm.nih.gov/geo; accession number GSE52754). ${ }^{9}$ The miRNAs are ordered in descending order of expression level in the liver. miRNAs shown in green and red represent hepatocyte- and LSEC-enriched miRNAs, respectively, with a difference of fourfold or greater. Initial candidates miR-122-5p, 335, and -511-3p are marked by arrows. B: Real-time RT-PCR analyses of miRNAs in the isolated LSECs and hepatocytes. Data are expressed as means \pm SEM. $n=3$ hepatocytes; $n=5$ LSECs.
} 
A
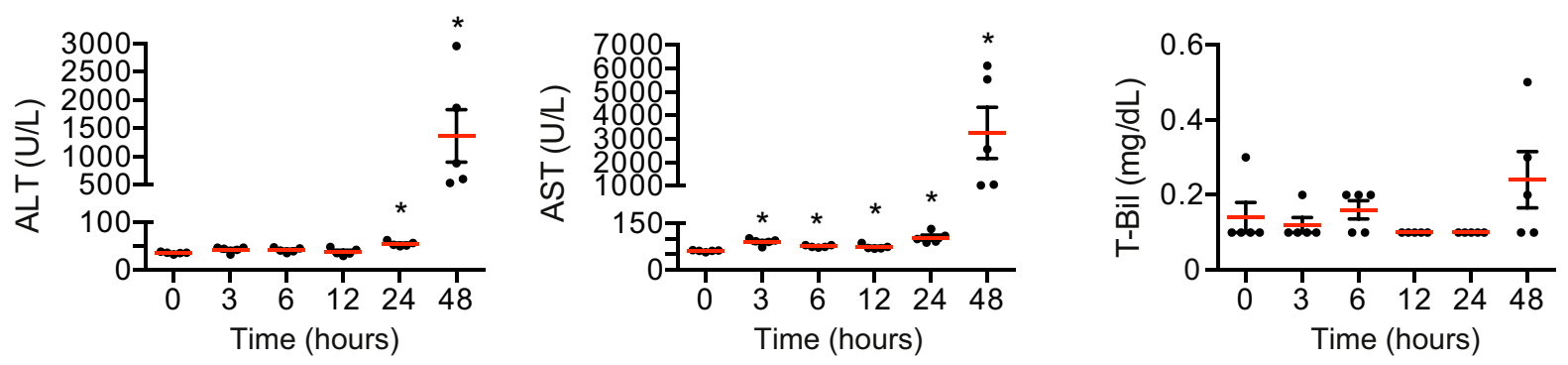

B

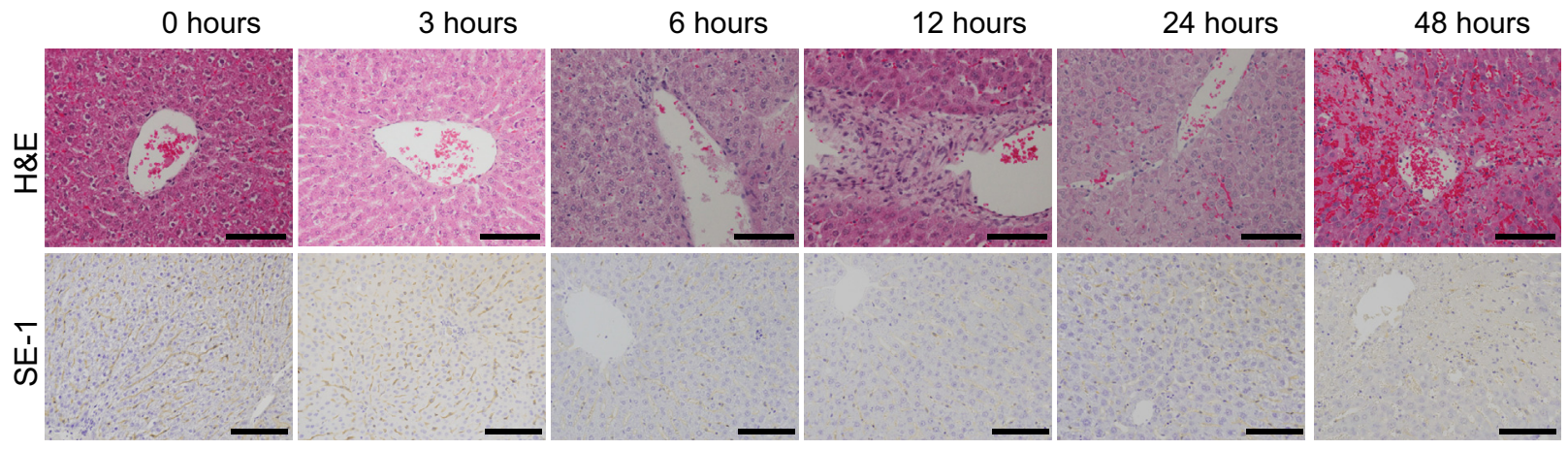

C
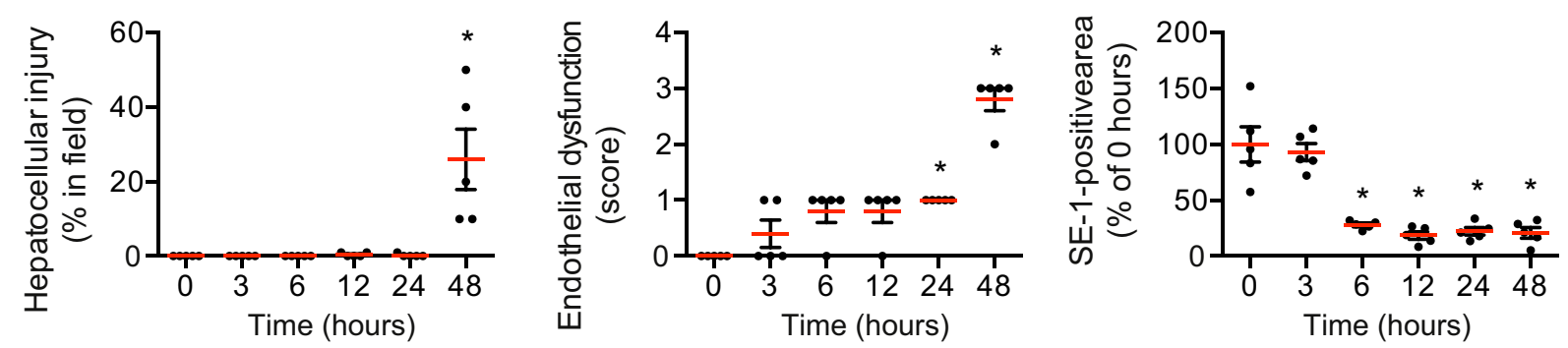

D
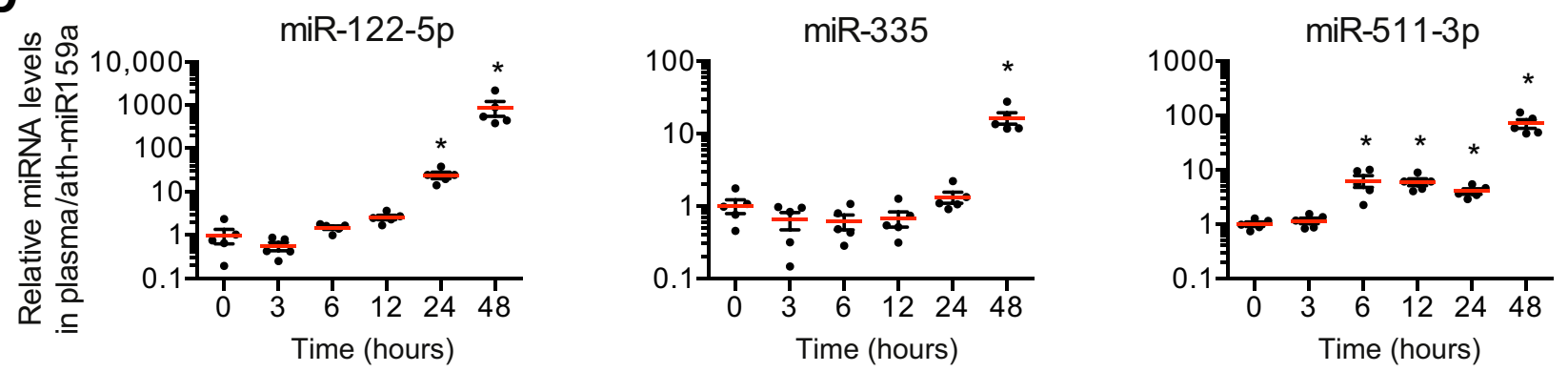

Figure 4 Plasma miRNA levels in monocrotaline-induced liver injury. Rats were orally administered monocrotaline at a dose of $160 \mathrm{mg} / \mathrm{kg}$. A: Alanine aminotransferase (ALT), aspartate aminotransferase (AST), and total bilirubin (T-Bil) levels in plasma. B: Hematoxylin and eosin (H\&E) staining and SE-1 immunohistochemistry of the livers. Additional images are provided in Supplemental Figure S1. C: Hepatocellular injury, score of endothelial cell dysfunction in central veins, and relative SE-1 expression levels. Endothelial dysfunction was scored as follows: score 0, absent; score 1, mild endothelial dysfunction; score 2, severe endothelial dysfunction; score 3, score $2+$ infiltration of regenerating endothelial cells and inflammatory cells; and score 4, score $3+$ vascular stenosis. D: miR-122-5p, miR-335, and miR-511-3p levels in plasma were quantified by real-time RT-PCR. Data are expressed as means \pm SEM. Each data point represents an individual animal. $n=5$ rats per time point. ${ }^{*} P<0.05$ versus the 0 -hour control. Scale bars $=100 \mu \mathrm{m}$ (B).

injury because specific expression of an miRNA of interest in a target organ is a prerequisite for an ideal biomarker as demonstrated successfully by liver-specific miR-122-5p for hepatocellular liver injury. ${ }^{10}$ The three-step approach adopted in identifying novel LSEC injury biomarkers was to i) compare miRNA expression in the isolated LSECs and hepatocytes, ii) cross-reference to the rat miRNA atlas, ${ }^{9}$ and iii) test in the two types of liver injuries, namely, 
A
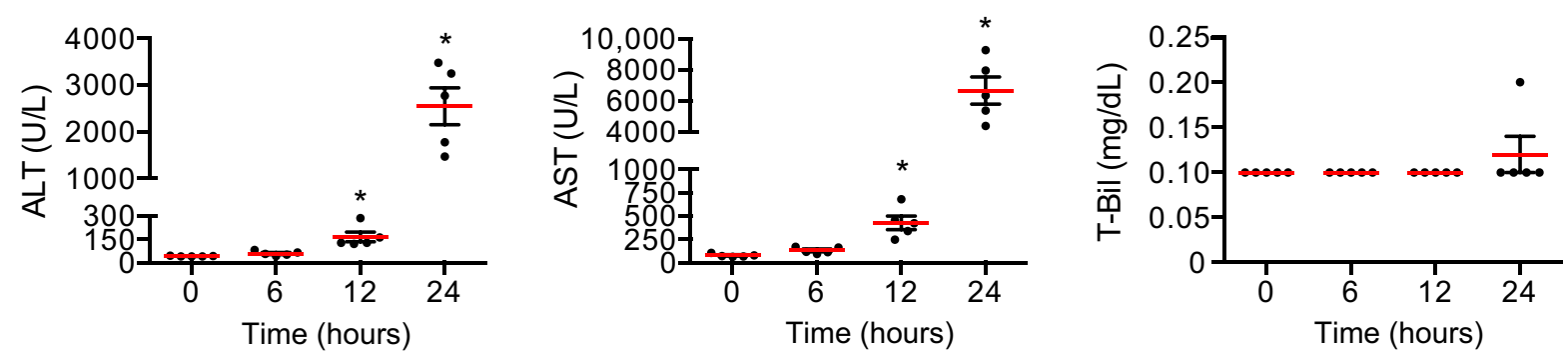

B

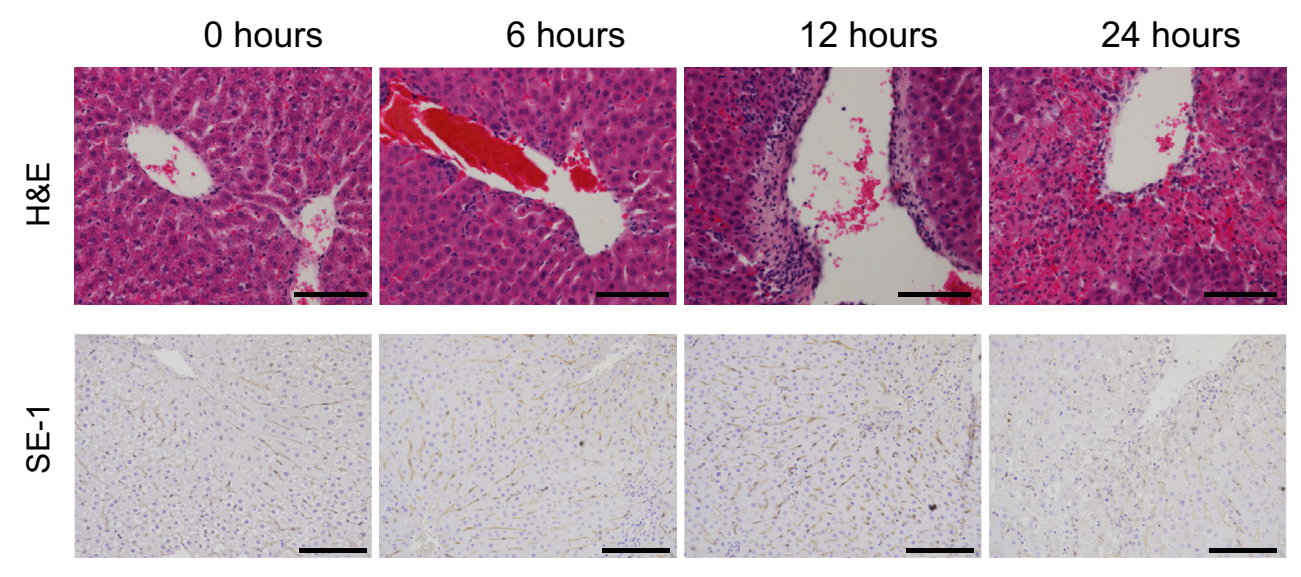

C

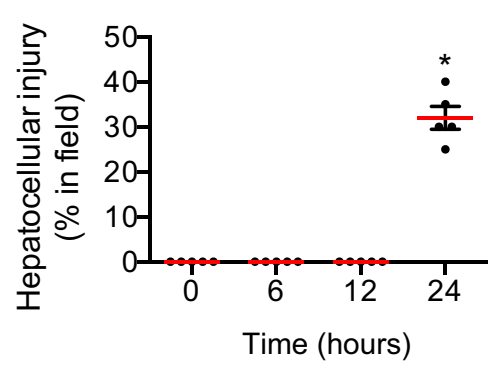

$\operatorname{miR}-122-5 p$

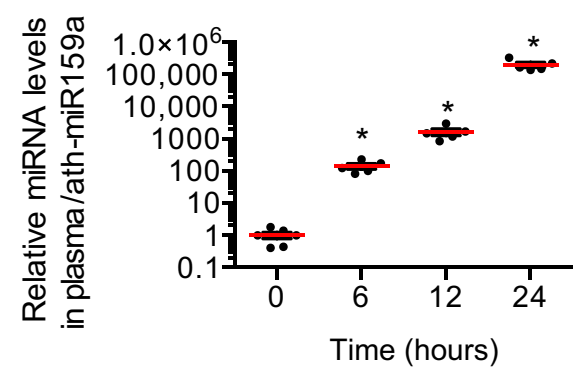

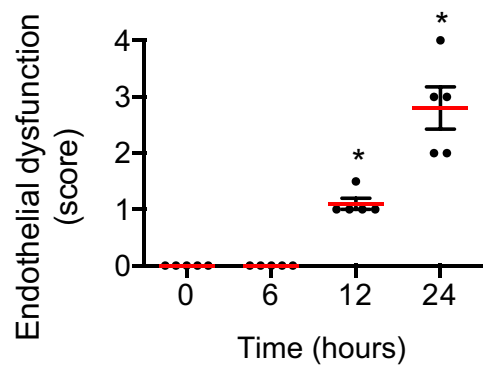

$\operatorname{miR}-335$

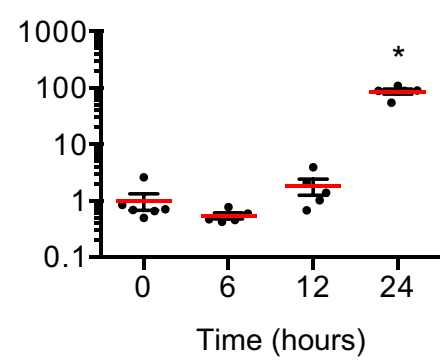

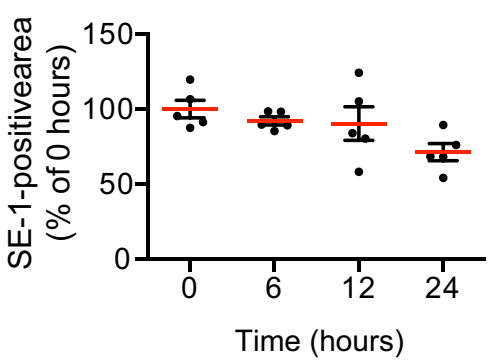

$\operatorname{miR}-511-3 p$

Figure 5 Plasma miRNA levels in thioacetamide-induced liver injury. Rats were orally administered thioacetamide at a dose of $100 \mathrm{mg} / \mathrm{kg}$. A: Alanine aminotransferase (ALT), aspartate aminotransferase (AST), and total bilirubin (T-Bil) levels in plasma. B: Hematoxylin and eosin (H\&E) staining and SE-1 immunohistochemistry of the livers. C: Hepatocellular injury and score of endothelial dysfunction in central veins and relative SE-1 expression levels. Endothelial dysfunction was scored as follows: score 0, absent; score 1, mild endothelial dysfunction; score 2, severe endothelial dysfunction; score 3, score $2+$ infiltration of regenerating endothelial cells and inflammatory cells; and score 4, score 3 + vascular stenosis. D: miR-122-5p, miR-335, and miR-511-3p levels in plasma were quantified by real-time RT-PCR. Data are expressed as means \pm SEM. Each data point represents an individual animal. $n=5$ rats per time point. ${ }^{*} P<0.05$ versus the respective 0 -hour control. Scale bars $=100 \mu \mathrm{m}$ (B). 
monocrotaline- and thioacetamide-induced liver injury models. By considering relative abundance and organ specificity in rats, two candidates, miR-335 and miR-511-3p, were selected as biomarkers for LSEC injury.

To test whether plasma levels of miR-335 and miR-511-3p as well as miR-122-5p can discriminate the hepatic damaged cell types, two rat models of liver injury were established by monocrotaline and thioacetamide treatment, which primarily cause LSEC and hepatocyte damage in the early phase, respectively. Monocrotaline is a toxic pyrrolizidine alkaloid contained in plants of the Crotalaria species, which causes hepatic SOS. ${ }^{20}$ The mechanism and pathophysiologic alteration of monocrotaline-induced SOS have been well examined in the rat model and in vitro as follows. ${ }^{21}$ The first step of SOS is LSEC-specific injury, with loss of fenestration and swelling, lining, and embolization of the cells and then blocked sinusoidal blood flow. The microvascular injuries induce typical SOS features, including central venous endothelial damage, hemorrhage, and centrilobular necrosis. In the monocrotaline-treated rats, reduction in the SE-1 protein expression precedes the endothelial damage in the central vein and hepatocellular death. LSECspecific miR-511-3p but not miR-335 in the plasma was increased at 6 hours, suggesting the presence of LSEC injury. At 24 hours, hepatocyte-specific miR-122-5p began to increase and the levels of three miRNAs were significantly increased at 48 hours, probably reflecting the presence of the devastating liver injury, including hepatocytes and LSECs. In clear contrast, miR-122-5p in the plasma was increased as early as 6 hours after thioacetamide treatment, which causes prominent hepatocellular injury at 24 hours, whereas miR-511-3p did not increase from 6 to 12 hours. In previous studies of thioacetamide-induced acute liver injury, hepatocellular necrosis was observed in the centrilobular region, ${ }^{22}$ supporting the observation. miR-511-3p was not sensitive for detecting hepatocellular liver injury. Taken together, the increase in plasma miR-511-3p levels would reflect the LSEC injury.

Although the expressions of miR-335 and miR-511-3p were enriched in rat LSECs, only miR-511-3p was increased in the plasma during the early phase of liver injury in monocrotalineinduced liver injury. A likely explanation is that the organ specificity of miR-335 is not confined to the liver. In fact, miR-335 is expressed in the thyroid, pituitary gland, and cerebrum, which have not been considered in this study. ${ }^{9}$ It is possible that most miR-335 present in the plasma may be derived from tissues other than the liver. Another possible reason may be the difference in the release mechanism of the two miRNAs into the plasma. miRNAs are known to exist in plasma in exosomes ${ }^{23}$ or apoptotic bodies ${ }^{24}$ or associated with high-density lipoprotein ${ }^{25}$ or Argonaute (Ago) proteins, ${ }^{26}$ although most (90\%) miRNAs in circulation are present in a non-membrane-bound form. ${ }^{26}$ Circulating miR-335s are present in exosomes and associated with Ago2 protein in humans, ${ }^{27}$ whereas those of miR-511-3p are unknown. Although species difference cannot be ignored in the release mechanism even in the identical miRNAs, the stability and amount of miRNAs in circulation may be affected.

SOS is often caused by chemotherapy or radiotherapy for hematopoietic stem cell transplantation, with the incidences ranging from $5 \%$ to $>50 \% .{ }^{28}$ For the clinical diagnosis of this syndrome, two primary scales (Baltimore and Seattle criteria) are currently used. ${ }^{29,30}$ Criteria from both scales include elevation of total serum bilirubin, painful hepatomegaly, ascites, and weight gain; however, these parameters are not specific to SOS. Because of the high mortality rate $(>80 \%)$ in the severe forms of SOS, ${ }^{6}$ early detection of SOS is a priority. Our study suggested the potential utility of plasma miR-511-3p as an early biomarker for SOS because the increase of this miRNA in plasma preceded that of T-Bil. This study may provide a basis for future follow-up investigations to determine whether there is translatability from animals to humans as biomarkers for SOS. For the successful clinical application, species differences in sequence, organ or cell specificity, and disease or injury specificity of miRNAs need to be appreciated. miR-511-3p is largely conserved between rats and humans, of which miR-511-3p in rats is one nucleotide shorter than that in humans. A recent collaborative study $^{31}$ on rat miRNA body atlas using Illumina miRNA sequencing by three institutes identified miR-511-3p as a liver-enriched miRNA by two of three institutes, supporting the observation that miR-511-3p is a liver-specific miRNA in rats. In contrast, tissue distribution of miR-511-3p in humans is not clearly understood. Human mature miRNA distribution in various organs, including the liver, has been reported in a few studies. ${ }^{19,32,33}$ Landgraf et a ${ }^{19}$ sequenced a small RNA library of 26 human organs with 1000 clones each in 2007. In their study, miR-511-3p was not detected. Ach et $\mathrm{al}^{32}$ performed Agilent microarrays containing 470 miRNAs of miRbase version 9 in nine organs. Recently, Ludwig et $\mathrm{al}^{33}$ also performed Agilent microarrays containing 1997 miRNAs of miRbase version 21 in 44 organs. However, the assay platforms of the two studies did not contain a probe for miR-511-3p. Although miR-511-3p is reported to be expressed in the human visceral adipose tissue ${ }^{34}$ and macrophages, ${ }^{35}$ no information on the miR-511-3p expression in other tissues is available. Thus, tissue distribution of miR-511-3p needs to be clarified to apply it with confidence as the translational biomarker in humans.

Regarding disease specificity, no clinical study reported the use of miR-511-3p as a disease or injury marker, although serum miR-511-5p was reported to be a diagnostic biomarker for combined pituitary hormone deficiency in children. ${ }^{36}$ In general, a functional guide strand of mature miRNA is loaded onto RNA-induced silencing complex together with Ago proteins, whereas the remaining passenger strand is degraded, ${ }^{37}$ resulting in the biased expression. In rats, miR-511-3p is relatively abundant in isolated LSECs (Figure 2A) and the liver ${ }^{9}$ compared with miR-511-5p, and is also abundant in humans, at least in breast cancer cells. ${ }^{38}$ Thus, further studies on disease or injury specificity of plasma miR-511-3p are needed. 
In summary, we provided miRNA expression profiles in the isolated hepatocytes and LSECs from rats and identified LSEC-specific miRNAs by considering organ specificity. The identified miR-511-3p was increased in the plasma during the early phase of monocrotaline-induced LSEC injury in rats but not during the early phase of thioacetamide-induced hepatocellular injury. Thus, the plasma miR-511-3p would represent the LSEC damage in rats. The same method used in this study would be applied in identifying biomarker studies in humans.

\section{Acknowledgments}

We thank Kaori Ushida, Yuko Mizuno, Miwa Itoh, and Eri Yorifuji (Nagoya University Graduate School of Medicine) for their technical advice regarding the histologic examinations.

S.O. and T.Y. designed the research; S.O., M.T., S.A., and Y.S. performed the experiments; S.O. and Y.S. handled the animals and their treatment; S.O. and K.T. analyzed the data; S.O. wrote the manuscript; T.Y. supervised the research project.

\section{Supplemental Data}

Supplemental material for this article can be found at https://doi.org/10.1016/j.ajpath.2017.12.007.

\section{References}

1. Alpini G, Phillips JO, Vroman B, LaRusso NF: Recent advances in the isolation of liver cells. Hepatology 1994, 20:494-514

2. Poisson J, Lemoinne S, Boulanger C, Durand F, Moreau R, Valla D, Rautou PE: Liver sinusoidal endothelial cells: physiology and role in liver diseases. J Hepatol 2017, 66:212-227

3. DeLeve LD: Liver sinusoidal endothelial cells and liver regeneration. J Clin Invest 2013, 123:1861-1866

4. DeLeve LD: Liver sinusoidal endothelial cells in hepatic fibrosis. Hepatology 2015, 61:1740-1746

5. Hornby RJ, Starkey Lewis P, Dear J, Goldring C, Park BK: MicroRNAs as potential circulating biomarkers of drug-induced liver injury: key current and future issues for translation to humans. Expert Rev Clin Pharmacol 2014, 7:349-362

6. Coppell JA, Richardson PG, Soiffer R, Martin PL, Kernan NA, Chen A, Guinan E, Vogelsang G, Krishnan A, Giralt S, Revta C, Carreau NA, Iacobelli M, Carreras E, Ruutu T, Barbui T, Antin JH, Niederwieser D: Hepatic veno-occlusive disease following stem cell transplantation: incidence, clinical course, and outcome. Biol Blood Marrow Transplant 2010, 16:157-168

7. Bentwich I, Avniel A, Karov Y, Aharonov R, Gilad S, Barad O, Barzilai A, Einat P, Einav U, Meiri E, Sharon E, Spector Y, Bentwich Z: Identification of hundreds of conserved and nonconserved human microRNAs. Nat Genet 2005, 37:766-770

8. Iwama H, Kato K, Imachi H, Murao K, Masaki T: Human microRNAs originated from two periods at accelerated rates in mammalian evolution. Mol Biol Evol 2013, 30:613-626

9. Minami K, Uehara T, Morikawa Y, Omura K, Kanki M, Horinouchi A, Ono A, Yamada H, Ohno Y, Urushidani T: miRNA expression atlas in male rat. Sci Data 2014, 1:140005
10. Wang K, Zhang S, Marzolf B, Troisch P, Brightman A, Hu Z, Hood LE, Galas DJ: Circulating microRNAs, potential biomarkers for druginduced liver injury. Proc Natl Acad Sci U S A 2009, 106:4402-4407

11. Dunn JC, Yarmush ML, Koebe HG, Tompkins RG: Hepatocyte function and extracellular matrix geometry: long-term culture in a sandwich configuration. FASEB J 1989, 3:174-177

12. Tokairin T, Nishikawa Y, Doi Y, Watanabe H, Yoshioka T, Su M, Omori Y, Enomoto K: A highly specific isolation of rat sinusoidal endothelial cells by the immunomagnetic bead method using SE-1 monoclonal antibody. J Hepatol 2002, 36:725-733

13. DeLeve LD, McCuskey RS, Wang X, Hu L, McCuskey MK, Epstein RB, Kanel GC: Characterization of a reproducible rat model of hepatic veno-occlusive disease. Hepatology 1999, 29:1779-1791

14. Yamaura Y, Nakajima M, Takagi S, Fukami T, Tsuneyama K, Yokoi T: Plasma microRNA profiles in rat models of hepatocellular injury, cholestasis, and steatosis. PLoS One 2012, 7:e30250

15. Krauskopf J, Caiment F, Claessen SM, Johnson KJ, Warner RL, Schomaker SJ, Burt DA, Aubrecht J, Kleinjans JC: Application of highthroughput sequencing to circulating microRNAs reveals novel biomarkers for drug-induced liver injury. Toxicol Sci 2015, 143:268-276

16. Rubbia-Brandt L, Lauwers GY, Wang H, Majno PE, Tanabe K, Zhu AX, Brezault C, Soubrane O, Abdalla EK, Vauthey JN, Mentha G, Terris B: Sinusoidal obstruction syndrome and nodular regenerative hyperplasia are frequent oxaliplatin-associated liver lesions and partially prevented by bevacizumab in patients with hepatic colorectal metastasis. Histopathology 2010, 56:430-439

17. Meister J, Schmidt MH: miR-126 and miR-126*: new players in cancer. Sci World J 2010, 10:2090-2100

18. Wang S, Aurora AB, Johnson BA, Qi X, McAnally J, Hill JA, Richardson JA, Bassel-Duby R, Olson EN: The endothelial-specific microRNA miR-126 governs vascular integrity and angiogenesis. Dev Cell 2008, 15:261-271

19. Landgraf P, Rusu M, Sheridan R, Sewer A, Iovino N, Aravin A, et al: A mammalian microRNA expression atlas based on small RNA library sequencing. Cell 2007, 129:1401-1414

20. Chojkier M: Hepatic sinusoidal-obstruction syndrome: toxicity of pyrrolizidine alkaloids. J Hepatol 2003, 39:437-446

21. DeLeve LD: Hepatic microvasculature in liver injury. Semin Liver Dis 2007, 27:390-400

22. Trennery PN, Waring RH: Early changes in thioacetamide-induced liver damage. Toxicol Lett 1983, 19:299-307

23. Valadi H, Ekstrom K, Bossios A, Sjostrand M, Lee JJ, Lotvall JO: Exosome-mediated transfer of mRNAs and microRNAs is a novel mechanism of genetic exchange between cells. Nat Cell Biol 2007, 9: 654-659

24. Zernecke A, Bidzhekov K, Noels H, Shagdarsuren E, Gan L, Denecke B, Hristov M, Koppel T, Jahantigh MN, Lutgens E, Wang S, Olson EN, Schober A, Weber C: Delivery of microRNA-126 by apoptotic bodies induces CXCL12-dependent vascular protection. Sci Signal 2009, 2:ra81

25. Vickers KC, Palmisano BT, Shoucri BM, Shamburek RD, Remaley AT: MicroRNAs are transported in plasma and delivered to recipient cells by high-density lipoproteins. Nat Cell Biol 2011, 13: 423-433

26. Arroyo JD, Chevillet JR, Kroh EM, Ruf IK, Pritchard CC, Gibson DF, Mitchell PS, Bennett CF, Pogosova-Agadjanyan EL, Stirewalt DL, Tait JF, Tewari M: Argonaute2 complexes carry a population of circulating microRNAs independent of vesicles in human plasma. Proc Natl Acad Sci U S A 2011, 108:5003-5008

27. Taylor DD, Gercel-Taylor C: MicroRNA signatures of tumor-derived exosomes as diagnostic biomarkers of ovarian cancer. Gynecol Oncol 2008, 110:13-21

28. Yakushijin K, Atsuta Y, Doki N, Yokota A, Kanamori H, Miyamoto T, Ohwada C, Miyamura K, Nawa Y, Kurokawa M, Mizuno I, Mori T, Onizuka M, Taguchi J, Ichinohe T, Yabe H, Morishima Y, Kato K, Suzuki R, Fukuda T: Sinusoidal obstruction syndrome after allogeneic hematopoietic stem cell transplantation: incidence, risk factors and outcomes. Bone Marrow Transplant 2016, 51:403-409 
29. McDonald GB, Sharma P, Matthews DE, Shulman HM, Thomas ED: Venocclusive disease of the liver after bone marrow transplantation: diagnosis, incidence, and predisposing factors. Hepatology 1984, 4:116-122

30. Jones RJ, Lee KS, Beschorner WE, Vogel VG, Grochow LB, Braine HG, Vogelsang GB, Sensenbrenner LL, Santos GW, Saral R: Venoocclusive disease of the liver following bone marrow transplantation. Transplantation 1987, 44:778-783

31. Smith A, Calley J, Mathur S, Qian HR, Wu H, Farmen M, Caiment F, Bushel PR, Li J, Fisher C, Kirby P, Koenig E, Hall DG, Watson DE: The Rat microRNA body atlas: evaluation of the microRNA content of rat organs through deep sequencing and characterization of pancreas enriched miRNAs as biomarkers of pancreatic toxicity in the rat and dog. BMC Genomics 2016, 17:694

32. Ach RA, Wang H, Curry B: Measuring microRNAs: comparisons of microarray and quantitative PCR measurements, and of different total RNA prep methods. BMC Biotechnol 2008, 8:69

33. Fehlmann T, Ludwig N, Backes C, Meese E, Keller A: Distribution of microRNA biomarker candidates in solid tissues and body fluids. RNA Biol 2016, 13:1084-1088
34. Estep M, Armistead D, Hossain N, Elarainy H, Goodman Z, Baranova A, Chandhoke V, Younossi ZM: Differential expression of miRNAs in the visceral adipose tissue of patients with nonalcoholic fatty liver disease. Aliment Pharmacol Ther 2010, 32: 487-497

35. Squadrito ML, Pucci F, Magri L, Moi D, Gilfillan GD, Ranghetti A, Casazza A, Mazzone M, Lyle R, Naldini L, De Palma M: miR-511-3p modulates genetic programs of tumor-associated macrophages. Cell Rep 2012, 1:141-154

36. Hu Y, Wang Q, Wang Z, Wang F, Guo X, Li G: Circulating microRNA profiles and the identification of miR-593 and miR-511 which directly target the PROP1 gene in children with combined pituitary hormone deficiency. Int J Mol Med 2015, 35:358-366

37. Winter J, Jung S, Keller S, Gregory RI, Diederichs S: Many roads to maturity: microRNA biogenesis pathways and their regulation. Nat Cell Biol 2009, 11:228-234

38. Chang HT, Li SC, Ho MR, Pan HW, Ger LP, Hu LY, Yu SY, Li WH, Tsai KW: Comprehensive analysis of microRNAs in breast cancer. BMC Genomics 2012, 13 Suppl 7:S18 